Artigo original

Hegemonia - Revista Eletrônica de Relações Internacionais do Centro Universitário Unieuro

ISSN: $1809-1261$

UNIEURO, Brasília, número 21, Julho-Dezembro de 2017, pp. 107-127.

Recebido em: 18/4/2017

Avaliado em 29/4/2017

Aprovado em: 12/5/2017

\title{
O Jogo Hermenêutico do Princípio da Responsabilidade de Hans Jonas no contexto sócioambiental
}

Mara Xavier de Almeida ${ }^{1}$ e José Felício Bergamin²

"O diálogo que está em curso se subtrai a qualquer fixação.

Mau hermeneuta é aquele que acredita que se pode ou deve

ficar com a última palavra".

Hans-Georg Gadamer

RESUMO: Com a escassez dos recursos naturais e a preocupação crescente com a degradação do meio ambiente surgiu a necessidade de uma análise mais aprofundada afim de se aplicar o Princípio Responsabilidade do pensador Hans Jonas em relação à ecologia. Os estudos da compreensão da linguagem na hermenêutica do instituto filosófico do Jogo Hermenêutico de Hans-Georg Gadamer, com as informações de caráter socioambiental fundamentam as concepções filosóficas do que é ética em relação ao princípio no âmbito ecológico. Nesse sentido, é objeto do tema é analisar o jogo hermenêutico utilizado pelo Estado na ausência de políticas públicas que visem à aplicação do Princípio Responsabilidade de Hans Jonas na esfera socioambiental. É importante enfatizar que o objetivo do artigo filosófico não é esgotar o assunto, nem mesmo detalhar de maneira aprofundada as questões que serão apresentadas, mas subsidiar a discussão sobre as principais convicções do filósofo Hans Jonas, quanto ao Princípio Responsabilidade como ética, direito e política, discutidas juntamente com o meio ambiente.

Palavras-chave: jogo hermenêutico; Responsabilidade de Hans Jonas; esfera socioambiental.

\footnotetext{
1 Mestranda em Filosofia e Política pela UNISINOS (Universidade do Vale do Rio dos Sinos), Escola de Humanidades. MBA em Direito e Política Tributária pela FGV (Fundação Getúlio Vargas). Advogada e docente no Centro Universitário UNIEURO, Brasília-DF.

2 Doutor e Mestre em Ciências Militares, Mestre, Especialista e Bacharel em Direito, Especialista em Docência do Ensino Superior, Psicopedagogia, Atualização Pedagógica, Supervisão Escolar e MBA-EXECUTIVO na FGV, Professor Dr. Nível III do Centro Universitário UNIEURO, Brasília-DF e do Centro Universitário ESTACIO-FACITEC de Brasília-DF.
} 
Artigo original

Hegemonia - Revista Eletrônica de Relações Internacionais do Centro Universitário Unieuro

ISSN: $1809-1261$

UNIEURO, Brasília, número 21, Julho-Dezembro de 2017, pp. 107-127.

ABSTRACT: Considering the lack of natural resources and the growing concern on the environmental degradation, emerged the necessity of a deep analysis on applying the Responsibility Principle of the thinker Hans Jonas regarding ecology. The studies of language understanding on hermeneutics of the philosophical institute from the Hermeneutic Game of Hans-Georg Gadamer, with the environmental-based information, gives support to the philosophical concepts of what is ethics facing the principle on an ecologic scope. In this sense, the theme object of the article is the study of the hermeneutic game used by the State in the lack of public policies the aims to the application of the Hans Jonas Responsibility Principle into the environmental sphere. It is important emphasize that the goal of the theme it is not to exhaust the subject, neither deeply detail the issues that will be presented, but contribute with the discussion on the main propositions of the philosopher Hans Jonas, the Responsibility Principle as ethics, law and politics, discussed along the environment.

Key words: hermeneutics; responsibility; environment.

\section{CONSIDERAÇÕES INICIAIS}

Como termo, para a articulação com as vertentes das teorias sociais contemporâneas, o presente texto utiliza o trabalho de Hans Jonas (2006) ao ponderar que o mundo e a humanidade viveria, nas últimas duas décadas, uma tensão entre dois discursos, visões de mundo e formas de fazer sociedade. Por um lado, um discurso racional e impulsionado por anseios de evolução e desenvolvimento da sociedade capitalista; por outro lado, discursos que falam daquilo que se exige para as gerações futuras, como a preservação do bioma e da fauna em que as palavras mais utilizadas são: jogo hermenêutico e meio ambiente.

O meio ambiente é responsabilidade do Estado e de todos nós; é, portanto, devida a aplicação do Princípio Responsabilidade de Hans Jonas em relação ao mesmo? Por que se preocupar somente com a ecologia quando já está degradada? A prevenção deve ser respeitada, mas, antes disso, o princípio da boa-fé deve ser observado tanto no plantio dos alimentos sem agrotóxicos, no reflorestamento, como na preservação de todo o complexo do bioma e da fauna.

Muito se discute sobre a responsabilização civil, administrativa e penal pelos danos causados ao meio ambiente, tanto no contexto internacional como nacional; porém, este trabalho de pesquisa trata de uma questão primordial, a aplicação do Princípio Responsabilidade, preconizado por Hans Jonas, em relação ao meio ambiente no contexto filosófico do jogo hermenêutico de Gadamer, como ausência de políticas públicas que visem à responsabilização da humanidade pelos danos ecológicos. 
Artigo original

Hegemonia - Revista Eletrônica de Relações Internacionais do Centro Universitário Unieuro ISSN: 1809-1261

UNIEURO, Brasília, número 21, Julho-Dezembro de 2017, pp. 107-127.

Percebe-se que há um jogo político quando não se responsabiliza o infrator pelos danos causados socioambientais. Portanto, o que está em pauta nesse artigo filosófico é a falta de responsabilização, característica desenvolvida por Hans Jonas em relação à omissão do Estado em criar efetivas e preventivas políticas públicas ecológicas. Nesse sentido:

\footnotetext{
No acontecimento do jogo, dá-se o surgimento do jogador, e não o contrário, o jogador ao se colocar na esfera do jogar possibilita a irrupção do jogo. Antes de escolher jogar, o jogador já foi escolhido pelo jogo que se abre às suas possibilidades, ou seja, o jogo já se mostra em uma dinâmica própria de maneira que o jogador possa nele entrar. Conforme Gadamer: O modo de ser do jogo, portanto, não implica a necessidade de haver um sujeito que se comporte como jogador, de maneira que o jogo seja jogado. Ao contrário, o sentido mais originário de jogar é o que se expressa na forma medial. Assim, por exemplo, costumamos falar que algo "está jogando" em tal lugar ou em tal momento, que está se desenrolando como jogo, que algo está em jogo (GADAMER, 2005, p. 157).
}

Assim, infere-se que o contorno do estudo será a avaliação da (in) efetividade das novas políticas públicas e da utilização do jogo hermenêutico, pelos governos em geral, para dilatar a ausência de responsabilização ambiental, especialmente, no panorama brasileiro em face dos desenraizados dos processos essenciais da sociedade, dos contingentes não incluídos, focalizado na falta de responsabilização pelos danos socioambientais, conforme argumenta Dworkin quando afirma que política pública é "aquele tipo de padrão que estabelece um objetivo a ser alcançado, geralmente uma melhoria em algum aspecto econômico, político ou social da comunidade". Isto significa que o objetivo socioambiental é atingir o desenvolvimento sustentável, abarcado no art. 225 da Constituição Federal de 1988, sem esquecer a importância primordial da preservação ambiental.

Também, pode-se argumentar com fundamento no princípio de boa-fé, típico da legislação brasileira atual, com objetivo de se buscar a ética, responsabilização socioambiental, proteção e prevenção do meio ambiente se ligam a uma outra questão do ponto de vista normativo, pois possuem dimensão moral, daí se pode analisar o Princípio Responsabilidade de Hans Jonas, que preconiza objetivos éticos em relação à ecologia. Diz o autor: 


\section{Artigo original}

Hegemonia - Revista Eletrônica de Relações Internacionais do Centro Universitário Unieuro

ISSN: 1809-1261

UNIEURO, Brasília, número 21, Julho-Dezembro de 2017, pp. 107-127.

Chamo de princípio a um padrão que deve ser observado não porque ele avançará ou assegurará um estado econômico, político ou social altamente desejável, mas porque ele é uma exigência de justiça ou equidade (fairness) ou de alguma outra dimensão da moralidade (DWORKIN, 2002, p. 127-128).

Portanto, ao explicar o papel dos princípios nos denominados hard cases, nos quais a diferença nos padrões normativos é mais evidente, Dworkin (2002) afirma que:

(...) em casos como esses, princípios desempenham uma parte essencial nos argumentos acerca de direitos e obrigações jurídicas particulares. Depois de decidido, podemos dizer que o caso é uma regra particular (e.g., a regra de que aquele que assassina não está capacitado a ser herdeiro da vítima). A regra, todavia, não existe antes que o caso tenha sido decidido. As cortes citam os princípios como justificação para adotar e aplicar uma nova regra (DWORKIN, 2002, p.136).

Destarte, conclui-se que o Princípio Responsabilidade de Hans Jonas pode ser analisado no âmbito ecológico, com a aplicação do jogo hermenêutico de Gadamer (2005), pois visa à responsabilização da sociedade no efetivo investimento em políticas públicas nesta conjuntura do meio ambiente.

\section{METODOLOGIA}

A metodologia, como ciência, é o conjunto de passos e métodos que serão utilizados para execução e alcance dos objetivos do processo investigatório. Neste sentido, a metodologia utilizada para analisar a evidenciação dos eventos econômicos relacionados ao meio ambiente será do tipo exploratória e descritiva. Exploratória, pois proporciona, segundo Gil (2002), uma visão geral sobre um fato, buscando torná-lo mais claro e descritivo, porque busca descrever a realidade do tema em questão, bem como suas características.

Por meio do estudo e aprofundamento do pensamento de Hans Jonas, o tema específico do artigo filosófico é compreender como se dá a reflexão sobre o fenômeno do jogo hermenêutico no contexto do Princípio Responsabilidade na esfera socioambiental. Outro 
Artigo original

Hegemonia - Revista Eletrônica de Relações Internacionais do Centro Universitário Unieuro ISSN: $1809-1261$

UNIEURO, Brasília, número 21, Julho-Dezembro de 2017, pp. 107-127.

objetivo específico é analisar a fundamentação da responsabilidade coletiva ambiental no contexto do avanço técnico-científico. $\mathrm{Na}$ concepção de Jonas, é importante considerar a interpretação filosófica podendo dimensionar as possibilidades de modificações constantes do meio ambiente, em todos os seus aspectos significativos diagnosticados a respeito do cenário de responsabilização pela prevenção do bioma, da fauna e dos recursos minerais universais.

Tal realidade se situa como um risco grandioso de efeitos, por vezes incalculáveis e irreversíveis, cujas consequências centram-se no futuro da humanidade; fomenta, por conseguinte, por um lado, o questionamento acerca do lugar e da importância da tecnologia e, por outro lado, atingindo o cerne dos sistemas de pensamento ético e moral vigentes, principalmente sob o ponto de vista da filosofia hermenêutica e seus complexos de ausência de políticas públicas de responsabilização do Estado pela devastação e destruição socioambiental, de forma que:

A inserção do sujeito humano no jogo se torna extremamente paradoxal, uma vez que "desfrutamos assim de uma liberdade de decisão que está correndo riscos e está sendo inapelavelmente restringida (GADAMER, 2005, p.160).

Sob tais circunstâncias, o saber se torna um dever prioritário, mais além de tudo o que anteriormente lhe era exigido; demais disso, o saber deve ter a mesma magnitude da dimensão causal do nosso agir, seja se utilizando do jogo hermenêutico, seja cobrando ações pontuais de preservação e responsabilização do Estado pela prevenção e sustentabilidade ecológica.

Mas o fato de que o jogador, sendo o poder público, não possa ter a mesma magnitude, isto é, de que o poder previdente permaneça atrás do saber técnico que confere poder ao agir, ganha o próprio governo significado político-social e ético no contexto socioecológico.

O hiato entre a força da previsão, por exemplo, da destruição do meio ambiente e o poder do agir produz um novo problema ético; portanto, reconhecer a ignorância se torna, então, o outro lado da obrigação do saber e, com isso, se caracteriza uma parte da ética que deve instruir o autocontrole, cada vez mais necessário, sobre o excessivo poder público. Entretanto, o ser humano é ser humano sempre, não há outra condição, nenhuma moral anterior vira-se obrigada a considerar a condição global da vida humana e o futuro distante, inclusive a existência 
Artigo original

Hegemonia - Revista Eletrônica de Relações Internacionais do Centro Universitário Unieuro ISSN: $1809-1261$

UNIEURO, Brasília, número 21, Julho-Dezembro de 2017, pp. 107-127.

do meio ambiente.

De acordo com o fato de que a política se utiliza do jogo hermenêutico (JONAS, 2006, p. 41) exige, numa palavra, uma nova concepção de direitos e deveres, para a qual nenhuma ética e metafísica antiga pode sequer oferecer os princípios, quanto mais uma doutrina acabada.

Uma das possibilidades reais da vida histórica universal, sob o ponto de vista filosófico, é o colapso social e ecológico; portanto a situação da sociedade de hoje é um problema de falta de responsabilização, além da conscientização do ser humano, pois as dificuldades fundamentais dizem respeito à humanidade como um todo. Isso significa dizer que a ética, na atualidade, tem de se articular levando em consideração toda a situação política-histórica e social e é caracterizada pela interdependência das nações no contexto de uma civilização técnico-científica.

Hans Jonas (2013), por exemplo, foca em uma visão da ética aplicada à conservação e à preservação do meio ambiente que constitui o projeto moderno, isto é, o ideal da instalação de um tipo do saber que se entende como possibilidade de dominação sobre a natureza em função da melhoria das condições de vida do ser humano, ou, mais radicalmente ainda, em função da emergência de responsabilizar a sociedade, com seus representantes, conduzido pelas forças emanadas do Estado.

Para essa concepção, saber é sinônimo de poder, cuja expressão suprema é a exploração técnica da natureza ambiental em função de sua subordinação aos fins humanos, o que paradoxalmente conduziu à sujeição completa a si mesmo sob o signo da catástrofe ecológica.

A problemática filosófica, ética e política do artigo em tela é a pesquisa e o estudo aprofundado de como o Princípio Responsabilidade de Hans Jonas fundamenta ações práticas de conservação e preservação socioambiental.

Além do enigma da etinicidade da civilização do jogo político do Estado, pelo segmento socioambiental, sob o ângulo da filosofia e do direito, Hans Jonas cria um novo conceito de preservação ambiental, com responsabilização das pessoas, do indivíduo público como agente de transformação e preservação ecológica.

Pelo estudo da filosofia, da ética e do direito aplicável se levantam os questionamentos de como se dão os mecanismos de responsabilização dos cidadãos pelos danos causados à 


\section{Artigo original}

Hegemonia - Revista Eletrônica de Relações Internacionais do Centro Universitário Unieuro ISSN: $1809-1261$

UNIEURO, Brasília, número 21, Julho-Dezembro de 2017, pp. 107-127.

ecologia, apresentados com ênfase na falta de ética nas políticas públicas, conforme a análise do pensador Hans Jonas no contexto do jogo hermenêutico (GADAMER, 1997, p. 15), portanto o questionamento é de como a população pode e deve realizar efetivamente a preservação/conservação do meio ambiente e a responsabilização do Estado pelo bem-estar social das pessoas. Entretanto, como contraponto à responsabilização, apresenta-se o seguinte problema:

O homem, ao jogar com planos e possibilidades, tem em absoluto sua liberdade colocada em xeque. E isso de duas maneiras distintas: uma porque, buscando se valer de sua própria liberdade de decisão ao poder escolher por coisas ou situações diversas, o homem sempre evitará se apoiar em algo que possa de alguma maneira o constranger, especialmente em situações de declarada seriedade. A segunda maneira é que, de forma geral, em seu cotidiano hodierno, o homem se ocupa de situações que, no fundo, não as toma a sério, e isso, pelo fato destas situações não serem imbuídas do risco de fazer escolhas mais perigosas, fazendo esse indivíduo se passar por frívolo (SANTOS, 2016).

Com efeito, acredita-se que o tema ainda não foi tratado, com o foco central que merece, não só a questão do jogo hermenêutico desenvolvido pelo filósofo Gadamer pelo poder público, pela falta de ética aplicada ao meio ambiente na Filosofia, na visão do Princípio Responsabilidade, do pensador Hans Jonas, bem como a responsabilização das pessoas pelos danos gerados ao bioma e aos recursos minerais universais ${ }^{3}$.

Busca-se, por meio da filosofia, da ética e do direito, a análise interdisciplinar da responsabilização da coletividade pelas catástrofes ecológicas, como terremotos, maremotos, efeito estufa, chuvas torrenciais, poluições sonoras, pluviais, visuais, enfim, todos os malefícios causados pelo homem à natureza, ou seja, visa desmascarar o jogo hermenêutico político em prol da coletividade.

Analisa-se o contexto ético, político e social pelos danos ambientais, e suas nuances que levam à falta de percepção, conscientização e entendimento da sociedade em todo o seu

${ }^{3}$ No Brasil existe a PNMA, que é a Política Nacional do Meio Ambiente. A PNMA define meio ambiente como o conjunto de condições, leis, influências e interações de ordem física, química e biológica, que permite, abriga e rege a vida em todas as suas formas. 
Artigo original

Hegemonia - Revista Eletrônica de Relações Internacionais do Centro Universitário Unieuro

ISSN: $1809-1261$

UNIEURO, Brasília, número 21, Julho-Dezembro de 2017, pp. 107-127.

contexto ecológico e tecnológico. Para isso, se utiliza de um estudo sistemático da aposta

hermenêutica do pensador Gadamer juntamente com o Princípio Responsabilidade de Hans

Jonas e sua proposta de moral para uma época terceirizada e cientificada não mais centrada no homem como sujeito, e sim no homem público, responsável pelo desenvolvimento de novas tecnologias de sustentabilidade, preservação e conservação ambiental.

A pesquisa, portanto, busca estudar a importância da preservação do meio ambiente, de forma sustentável, visando à proteção das presentes e futuras gerações (GADAMER, 1997). Assim, a relevância de se interpretar o jogo hermenêutico na esfera ambiental, bem como suas características de ausência responsabilização preconizada por Hans Jonas da civilização pela crise ecológica desse século.

Será qualitativa a abordagem usada para a análise dos documentos, doutrinas e jurisprudências, relacionadas ao tema ambiental de pesquisa, pois, de acordo com Richardson (1999), não há uso de técnicas estatísticas no processo de análise, ou seja, é caracterizado pelo emprego de análises filosóficas do Princípio Responsabilidade de Hans Jonas, com base na importância de preservar a integridade da natureza como requisito de sobrevivência das presentes e futuras gerações.

\section{JOGO HERMENÊUTICO NO CONTEXTO SOCIOAMBIENTAL}

A hermenêutica metodológica consiste na arte da interpretação, na técnica de agir, de ser; portanto, é a hermenêutica um instrumento de explicação dos acontecimentos. Ela se atém apenas ao significado, que traz o seu sentido conotativo, explícito no dicionário, ou na Wikipédia atual. De tal sorte, o jogo hermenêutico de Gadamer ${ }^{4}$ pode ser definido como o descobrir, isto é,

\footnotetext{
${ }^{4}$ Usando como referência o pensamento de Hans-Georg Gadamer, este artigo se propõe apresentar resumidamente o conceito de jogo, arte e linguagem para hermenêutica filosófica. O que é jogo? O jogo pode ter um sentido filosófico? O que o jogo tem? Qual a relação entre jogo e arte? Que movimento há na arte, arte e na linguagem, segundo Gadamer? Estas são questões que serão tratadas diretamente aqui, não no sentido de se encontrar qual o jogo ou qual o método de jogar, pois o que se apresenta é a ontologia do jogo, da arte e a linguagem como instância ontológica. Aliás, sobre o método e jogo já se coloca uma questão inicial na hermenêutica filosófica. No próprio título do livro de Gadamer, editado pela editora Vozes, aqui no Brasil, Verdade e Método - traços fundamentais de uma hermenêutica filosófica, já se utiliza o termo método, construindo então um título bastante instigante pela associação de duas ideias caras a filosofia: verdade e método.
} 


\section{Artigo original}

Hegemonia - Revista Eletrônica de Relações Internacionais do Centro Universitário Unieuro ISSN: 1809-1261

UNIEURO, Brasília, número 21, Julho-Dezembro de 2017, pp. 107-127.

como interpretar as leis e tratados jurídicos de modo a responsabilizar o poder público e toda a sociedade pelo meio ambiente.

O filósofo Luiz Rohden (2012) afirma que "Quem joga vive a tensão produtiva entre a física e a metafísica, entre o cotidiano e o transcendental, entre o real e o irreal”. Portanto, podese analisar o jogo das políticas públicas em relação à ecologia como essa cobrança políticajurídica da sociedade em preservar o meio ambiente, em contrapartida à realidade vivida, ou seja, à falta de empenho público para inserir limites e responsabilização pelos danos causados ao bioma. Dessa forma:

O jogo distingue-se da vida comum pelo lugar, pela duração, por seu isolamento em relação a ela. Ocorrendo dentro de certos limites de tempo e de espaço, ele traça um caminho e um sentido próprios, distinguível do cotidiano (ROHDEN, 2012, p.122-123).

Há uma preponderância ou primazia de aplicação do direito ao meio ambiente ecologicamente equilibrado sobre o dever de tutela e promoção da confiança legítima no tráfego jurídico. Essa precedência se tira do texto constitucional, das leis infraconstitucionais, da doutrina que se trata do diálogo aprofundado pelo filósofo Gadamer e, sobretudo, da jurisprudência dos tribunais pátrios, especialmente do Superior Tribunal de Justiça, encarregado de unificar a interpretação da legislação federal. Nesse contexto:

As realizações interpretativas simbólicas e culturais tornam-se num princípio essencial do diálogo. Será, pois, para Gadamer o diálogo, não o contrário, o mais importante facto da cultura. Todavia o texto "A inaptidão ao diálogo" abre com os fenómenos técnicos com que essa aptidão acaba: "Algo de brutal como um desalinho, o de estar desalinhado, permanece ligado a todo o chamamento telefónico, ainda que o interlocutor assegure vivamente que o chamamento o regozija (SANTOS, 2016).

As preocupações mundiais com o meio ambiente e a globalização da economia, principalmente após os anos 90, fizeram com que a sociedade voltasse sua atenção para as questões socioambientais e para a sustentabilidade de suas operações. Demais disso, a escassez de recursos naturais foi outro motivo que forçou as empresas a encontrarem soluções 


\section{Artigo original}

Hegemonia - Revista Eletrônica de Relações Internacionais do Centro Universitário Unieuro ISSN: 1809-1261

UNIEURO, Brasília, número 21, Julho-Dezembro de 2017, pp. 107-127.

ambientalmente corretas e economicamente viáveis com o intuito de reduzir os desperdícios, típicos do capitalismo moderno.

O conceito de desenvolvimento sustentável deve satisfazer as necessidades do presente sem comprometer a capacidade das futuras gerações em alcançar suas próprias indigências, daí a apuração da responsabilidade, tanto administrativa, civil e penal, através da aplicação do Princípio Responsabilidade de Hans Jonas, como forma de manter a capacidade de fruição dos recursos naturais para as gerações futuras.

Baseado na responsabilidade civil pelo dano ambiental, deve-se considerar o direito ao equilíbrio socioambiental como direito humano fundamental, por dizer respeito à garantia de vida digna das presentes e futuras gerações. Ademais, deve-se ressaltar a função social da propriedade, do contrato e da empresa, a condicionar seu exercício aos interesses coletivos, a ubiquidade ambiental, interpretando o jogo hermenêutico recomendado por Gadamer (2005) como um jogo político-social que não responsabiliza a sociedade pela precaução ambiental. Argumenta o filósofo que:

Por isso mesmo, o jogo possui a capacidade de sempre revigorar-se em uma constante repetição, possuindo, portanto, regras próprias. E, ao passo que o jogo possibilita instaurar uma constante repetição de determinadas ações, são justamente essas ações repetidas que deixam que se mostre o diferente: pelas mesmas jogadas nasce o diferente, não devendo perder de vista o fato de que, embora se repita uma jogada (ação) aparentemente igual às demais, a configuração fluída de sentidos por ela revelada está sempre imbuída de um viço de novidade. Contudo, ainda que esteja em constante mudança de perspectivas, o jogo não perde o caráter das regras que o limitam. É justamente as regras que o compõem que fazem do jogo algo dúbio: quer um fenômeno instável, se visto pela ocular subjetiva (já que cada indivíduo defronta-se com uma perspectiva distinta do jogo), quer um fenômeno limitado a determinado campo de realização, como no esporte - em um jogo qualquer, embora se conheça as regras, o jogador as reinventa a fim de adequar-se a determinada situação que o jogo apresenta. Consequentemente, está além da apreensão estética, cabendo falar em jogo (SANTOS, 2016). 
Artigo original

Hegemonia - Revista Eletrônica de Relações Internacionais do Centro Universitário Unieuro ISSN: $1809-1261$

UNIEURO, Brasília, número 21, Julho-Dezembro de 2017, pp. 107-127.

Além disso, deve-se preconizar a onipresença do meio ambiente em qualquer ato decisório ou negócio privado, bem como os princípios da prevenção e precaução, a determinar o evitamento ou mitigação dos riscos ao ambiente, o Princípio Responsabilidade de Hans Jonas (2006) em casos destruição ao meio ambiente, capaz de imputar a encargo pela simples realização da atividade, é correto e imprescindível inferir que o titular de um direito não poderá invocar, em linha de princípio, a boa-fé e a confiança em desfavor do bem ambiental.

Pode-se concluir, assim, que se tem maior invocação, mesmo que não seja expressa, a tese da adequabilidade das normas jurídicas e a teoria da integridade do direito de Dworkin (2002), sendo certo que se verifica uma construção de práticas sociais e institucionais, sobretudo das altas instâncias judiciárias, em favor do bem ambiental.

Cabe, então, à sociedade e aos órgãos estatais legitimados, não utilizar o jogo hermenêutico para fugir da responsabilidade público-social de exercer com maior assiduidade o papel de fiscais e promotores da dignidade ambiental em seu próprio benefício e das gerações futuras, estas sem voz e força para agir em favor da vida presente e duradoura.

\section{PRINCÍPIO RESPONSABILIDADE DE HANS JONAS}

Desenvolvido pelo filósofo Hans Jonas, o Princípio Responsabilidade fundamenta ações práticas, baseadas na ética e na inovação tecnológica, procura solucionar a questão da vulnerabilidade da sociedade frente ao jogo hermenêutico utilizado pelo Estado para escapar da responsabilidade de se preservar a natureza. Isso mascara os problemas ecológicos decorrentes dos danos causados pela coletividade, ou seja, há uma ausência do Estado em responsabilizar tanto o próprio governo e sua gestão e, a ausência de leis efetivas e também a sociedade pela grave crise ecológica e os inúmeros problemas ambientais.

A questão principal a ser examinada neste artigo consiste na problemática filosófica, ética e política fundada na influência do Princípio Responsabilidade, do filósofo alemão, Hans Jonas (2006), na incumbência da coletividade pelos danos socioambientais, na falta de políticas públicas de sua preservação e, também o desenvolvimento sustentável. 
Artigo original

Hegemonia - Revista Eletrônica de Relações Internacionais do Centro Universitário Unieuro

ISSN: 1809-1261

UNIEURO, Brasília, número 21, Julho-Dezembro de 2017, pp. 107-127.

Diante do exposto, esse artigo filosófico traduz a pesquisa e o estudo aprofundado de como ocorre a aplicação do Princípio Responsabilidade do alemão Hans Jonas, do progresso técnico-científico da sociedade sob a análise do jogo hermenêutico de Gadamer (2005) dessa inovação tecnológica no contexto da responsabilidade pela intervenção técnica do homem ambiental. Resta clara a indagação de como o Princípio Responsabilidade de Hans Jonas fundamenta as ações práticas de conservação e preservação do meio ambiente?

Além do problema da etinicidade aplicada ao meio ambiente, tanto na ausência de política pública, característica do jogo hermenêutico, como tecnológica, sob o ângulo da Filosofia de Hans Jonas e do Direito. Assim, o estudo do Princípio Responsabilidade visa responsabilizar o homem público frente à crise ecológica e tecnológica no contexto socioambiental atual.

Há que se analisar o papel ético do homem público em face do Princípio da Responsabilidade de Hans Jonas, e a falta de sustentabilidade das novas tecnologias científicas empregadas no desenvolvimento da sociedade civil. Diante dessa análise preliminar, cabe avaliar toda a aplicabilidade da ética, segundo o filósofo, junto ao meio ambiente, e a responsabilização da coletividade pela crise ambiental vivida no século XXI.

As atividades econômicas e de caráter de inovação tecnológica, para uma época tecnicizada e cientificizada não mais centralizada no sujeito, porque, segundo Hans Jonas (2006), as éticas tradicionais sustentadas no sujeito não dão conta de tratar da questão das inovações científicas e tecnológicas, tanto do ponto de vista de sua fundamentação como de sua aplicação. Afirma o autor:

É importante notar que sempre que se fala em jogo, até mesmo em âmbito gramatical, somos impelidos a entender que é um sujeito quem joga ${ }^{5}$, e que, por isso, comanda, quase que integralmente, a situação experienciada. O jogo não é de forma alguma um tipo de representação ou situação passível de domínio. Gadamer afasta-se de qualquer interpretação do conceito de jogo que esteja na esfera da subjetividade. Não se trata de um jogo no qual um jogador qualquer escolhe fazer o que lhe é aprazível ou até mesmo lógico. Antes disso, o próprio

\footnotetext{
${ }_{5}^{5}$ Basta-se atentar, basicamente, com a conjugação do verbo jogar. O presente do indicativo do verbo jogar em português é: Eu jogo/ Tu jogas/ Ele joga/ Nós jogamos/ Vós jogais/ Eles jogam. O pronome pessoal passa a ideia do sujeito no domínio da ação.
} 
Artigo original

Hegemonia - Revista Eletrônica de Relações Internacionais do Centro Universitário Unieuro

ISSN: $1809-1261$

UNIEURO, Brasília, número 21, Julho-Dezembro de 2017, pp. 107-127.

modo de ser do jogo (no caso, da dinâmica própria da obra de arte) prescinde

da consciência do jogador no que concerne às suas vontades e escolhas

(GADAMER, 2005).

Considerados o poder e o ampliado potencial de seu fazer técnico, Hans Jonas pensa um novo imperativo ético, muito mais adequado aos desafios colocados pela centralidade da técnica nos tempos hodiernos, pertinente ao novo tipo de agir humano e voltado para o novo tipo de sujeito atuante, sendo expresso da seguinte forma: "Aja de modo a que os efeitos da tua ação sejam compatíveis com a permanência de uma autêntica vida humana sobre a Terra". Com tal imperativo ético, Hans Jonas (2006) busca argumentar a tese do controle aos abusos, além da omissão do Estado em desenvolver técnicas que tenha a possibilidade de realizar, pretendendo nortear o agir humano para o caminho de um progresso ecologicamente responsável.

Nesse sentido, é de se ressaltar ainda, outro princípio filosófico, quando Keinert (2007) aponta o princípio arendtiano de que a experiência da liberdade se encontra conectada à condição de igualdade entre aqueles que participam da esfera pública.

Trata-se do princípio da isonomia que afirma a igualdade como atributo específico da política. Este título aponta a possibilidade "do viver como ser distinto e singular entre iguais" (ARENDT, p. 191). Diante de tal afirmação filosófica de Arendt, tem-se que a interpretação hermenêutica do jogo político que se trata do poder público se responsabilizar por ações de preservação por parte do Estado e dos cidadãos pela degradação ambiental.

\section{O PANORAMA BRASILEIRO DO MEIO AMBIENTE}

A preocupação com a degradação do meio ambiente ${ }^{6}$ também pode ocorrer em função da inobservância do princípio da boa-fé quando da realização dos contratos ambientais. Isto porque, parece fértil o interesse, da doutrina e da jurisprudência, sobre a ausência de uma efetiva

\footnotetext{
${ }^{6} \mathrm{Na}$ ecologia, o meio ambiente é o panorama animado ou inanimado onde se desenvolve a vida de um organismo. No meio ambiente existem vários fatores externos que têm uma influência no organismo. A ecologia tem como objeto de estudo as relações entre os organismos e o ambiente envolvente. http://www.significados.com.br/meioambiente/ Acessado em: 27.2.2016.
} 
Artigo original

Hegemonia - Revista Eletrônica de Relações Internacionais do Centro Universitário Unieuro ISSN: $1809-1261$

UNIEURO, Brasília, número 21, Julho-Dezembro de 2017, pp. 107-127.

política pública de responsabilização do Estado em relação à preservação/conservação do bioma, seja em textos de juristas de revistas especializadas e na doutrina filosófica e jurídica, especialmente os de Direito Ambiental, Civil e Administrativo e até nos votos dos integrantes dos tribunais superiores do país.

Neste sentido, devem ser criadas leis e normas, no âmbito nacional e internacional, que introduzam várias mudanças relacionadas às práticas que impactam o meio ambiente e exigir das empresas o reconhecimento de passivos ambientais como, por exemplo, a recuperação dos recursos degradados pelas atividades operacionais.

De conquista e assimilação recente, há quase quarenta anos nos círculos do discurso jurídico, desde a sua inserção na Declaração de Estocolmo, das Nações Unidas ${ }^{7}$, em 1972, vem também sendo lembrado com bastante frequência nos escaninhos judiciais e administrativos e, também, legislativos, devido a sua essencial ou vital importância, pois afeto à própria sobrevivência da espécie humana e da vida como um todo em nosso planeta.

Outro objetivo é esboçar as principais teses que o conhecimento jurídico se levanta, neste início de século, sobre a solução para os casos de colisão entre direitos fundamentais à proteção à fauna, à flora e os recursos minerais, extraídos da Constituição, quando então se analisa as teses da ponderação entre valores, tal como preconizada por Robert Alexy (2008, p. 669), e da teoria da integridade do direito, conforme esposada por Dworkin (2002), que pode ser aplicada ao bioma universal.

A partir de 1972 com a Conferência de Estocolmo, conhecida também como Declaração da Conferência das Nações Unidas sobre o Meio Humano o pensamento econômico que predominava nas organizações começou a se voltar também para questões sociais e ambientais.

Em 1983, com a criação da Comissão Mundial sobre Meio Ambiente e Desenvolvimento (CMMAD) pela Organização das Nações Unidas (ONU), iniciou-se a difusão

\footnotetext{
${ }^{7}$ Para as Nações Unidas, meio ambiente é o conjunto de componentes físicos, químicos, biológicos e sociais capazes de causar efeitos diretos ou indiretos, em um prazo curto ou longo, sobre os seres vivos e as atividades humanas. http://www.significados.com.br/meio-ambiente/ Acessado em 27.2.2016.
} 
Artigo original

Hegemonia - Revista Eletrônica de Relações Internacionais do Centro Universitário Unieuro

ISSN: 1809-1261

UNIEURO, Brasília, número 21, Julho-Dezembro de 2017, pp. 107-127.

desses novos pensamentos, através do Relatório Nosso Futuro Comum, o qual foi responsável pelas primeiras conceituações formais e sistematizadas sobre o desenvolvimento sustentável.

Com essas novas normas impostas pelos governos, as empresas se viram obrigadas a se preocupar com a degradação e poluição que suas atividades provocam ao meio ambiente, porque caso não fossem obedecidos os padrões e normas legais, isto poderia conduzir a punições. Dentre outras iniciativas a favor do meio ambiente podemos citar o Programa Produção Mais Limpa, introduzido pelo Programa das Nações Unidas para o Meio Ambiente (PNUMA); a Agenda 21, resultado da Conferência das Nações Unidas realizada no Rio de Janeiro em 1992 e o protocolo de Kyoto em 1997.

Quanto aos aspectos legais brasileiros, deve ser considerada a evolução das normas e regulamentações quando se trata da interação entre as empresas e o meio ambiente ${ }^{8}$. Desta forma, há várias leis que tratam de assuntos relacionados à conservação e preservação do meio ambiente em nosso país, tais como a Lei 6.938/1981, alterada pela Lei 10.165/00, que trata sobre a Política Nacional do Meio Ambiente e a Lei 9.985/00 que dispõe sobre a criação das Unidades de Conservação.

A preocupação com a degradação do meio ambiente pode ocorrer em função dos desrespeitos das leis e tratados, há uma necessidade de preservação da flora e fauna nativa e dos recursos minerais segundo um conceito filosófico do entendimento da precaução como boa-fé, em contradição ao Princípio Responsabilidade de Hans Jonas, com o jogo hermenêutico de Gadamer (SANTOS, 2016) consagrando a ausência de políticas públicas por parte do Estado visando evitar a degradação da natureza no contexto geral.

Ao fim, intenta-se auferir que o direito ao meio ambiente ecologicamente equilibrado goza de uma posição de primazia ou prevalência sobre o direito de proteção à confiança legítima, de modo que o primeiro só cederá espaço, no caso concreto, para o segundo, quando a

\footnotetext{
${ }^{8}$ Meio ambiente é um conjunto de unidades ecológicas que funcionam como um sistema natural, e incluem toda a vegetação, animais, micro-organismos, solo, rochas, atmosfera e fenômenos naturais que podem ocorrer em seus limites. Meio ambiente também compreende recursos e fenômenos físicos como ar, água e clima, assim como energia, radiação, descarga elétrica, e magnetismo. http://www.significados.com.br/meio-ambiente/. Acesso em 28.2.2016.
} 


\section{Artigo original}

Hegemonia - Revista Eletrônica de Relações Internacionais do Centro Universitário Unieuro ISSN: $1809-1261$

UNIEURO, Brasília, número 21, Julho-Dezembro de 2017, pp. 107-127.

lógica do melhor argumento ou do maior peso estiverem em favor do dever de preservação da ecologia.

\section{CONSIDERAÇÕES FINAIS}

O fato de que o Estado utiliza o jogo hermenêutico para responsabilizar toda a sociedade pelos danos socioambientais exige, numa palavra, uma nova concepção de direitos e deveres, para a qual nenhuma ética e metafísica antiga pode sequer oferecer os princípios, como o da Responsabilidade do filósofo Hans Jonas, quanto mais uma doutrina acabada (JONAS, 2006). Por outro lado:

O objectivo do diálogo é apresentado como consistindo na realização do pensar. O diálogo espera a aquiescência dos interlocutores em termos de se libertarem do seu desenvolvimento individual através do problema a que eles são submetidos. Será para se "ser levado" por isso, fazendo intervir o exame do que se responde, a pôr em jogo a resposta e fazer prova desta. É uma orientação que decorre da debilidade da resposta. É uma orientação que se destina a dar força de pensamento à própria resposta (GADAMER, 2005, p. 36).

Portanto, nas palavras do filósofo alemão, é de como a população deve realizar, na prática, a preservação/conservação do meio ambiente, visando a responsabilização do Estado pelo bem-estar social dos cidadãos, bem como a incumbência do poder público de responder pelos danos gerados ao meio ambiente.

Nesse sentido, o filósofo Gadamer valoriza o diálogo, a discussão que pode ser aplicada na formulação de ações de preservação ambiental pelo governo e pela sociedade em geral:

Gadamer fala de uma compreensão que não é igual à coisa: "nós estamos comprometidos com qualquer coisa e é precisamente por isso que nos compromete que nos abrimos para qualquer coisa de novo, de outro, de verdadeiro". Esta compreensão é, fundamentalmente, uma experiência do compromisso. Que o diálogo arquitecta, em termos do privilegiar o alargamento do horizonte de um compreender. Devemos pensar que este é a 


\section{Artigo original}

Hegemonia - Revista Eletrônica de Relações Internacionais do Centro Universitário Unieuro

ISSN: 1809-1261

UNIEURO, Brasília, número 21, Julho-Dezembro de 2017, pp. 107-127.

contrapartida da estreiteza de toda a experiência de raiz? (GADAMER, 2005, p. 36).

Do fascínio pelo eminente poder de transformação e intervenção do homem público, percebe-se não haver condições de as éticas tradicionais, as quais, alicerçam-se sobre a perspectiva antropocêntrica, nortearem as ações humanas. Esse desajuste ambiental, por ausência de ações preventivas do governo, só poderá ser corrigido, no entendimento do pensador Hans Jonas, pela elaboração de uma nova ética ambiental, a saber:

\footnotetext{
A presença do homem no mundo era um dado primário e indiscutível de onde partir toda ideia de dever referente à conduta humana: agora, ela própria tornou-se um objeto de dever - isto é, o dever de proteger a premissa básica de todo o dever, ou seja, precisamente a presença de meros candidatos a um universo moral no mundo físico do futuro; isso significa, entre outras coisas, conservar este mundo físico de modo que as condições para uma tal presença permaneçam intactas; e isso significa proteger a sua vulnerabilidade diante de uma ameaça dessas condições (JONAS, 2006, p. 45).
}

O poder técnico de preservação e conservação ambientais se estende às consequências e aos resultados da ação, caracterizando, por sua vez, o poder ampliado da ação humana, constata os indícios da importância e da grandeza não mais delimitável no espaço e no tempo. Diante disso, nas palavras do pensador alemão:

Ao ultrapassar o horizonte da vizinhança espaço-temporal, esse alcance ampliado do poder humano rompe o monopólio antropocêntrico da maioria dos sistemas éticos anteriores, sejam religiosos ou seculares (JONAS, 2013, p. $55)$.

Logo, a técnica de criação de políticas públicas se constroi como um experimento marcado pela ambivalência, pois não nos é possível reconhecer todas as suas consequências dos danos ambientais, porque tal abrangência foge, inclusive, do controle das mãos do ser humano, tomando em consideração a magnitude e a ampliação enquanto possibilidade de o poder fazer humano, uma vez que, segundo Hans Jonas: 
Artigo original

Hegemonia - Revista Eletrônica de Relações Internacionais do Centro Universitário Unieuro ISSN: $1809-1261$

UNIEURO, Brasília, número 21, Julho-Dezembro de 2017, pp. 107-127.

(...) a 'ambivalência' da técnica está estreitamente ligada à sua 'grandeza', isto é, à desmesura de seus efeitos no espaço e no tempo (JONAS, 2013, p. 59).

Ou seja, mesmo que o indivíduo tenha uma conduta fundamentada em uma boa intenção, esta não se constituiria ainda em uma garantia segura de que as consequências estariam sempre no âmbito do previsível e do calculável (OLIVEIRA, 2012, p. 3). Isto é, seriam as ações práticas científico-tecnológicas que causam a relevante crise ambiental do século XXI, decorrente da relação deturpada do homem-natureza na atualidade.

Pode-se concluir, assim, que aqui tem maior invocação, mesmo que não seja expressa, a tese da adequabilidade das normas jurídicas e a teoria da integridade do direito de Dworkin (2002), sendo certo que se verifica uma construção de práticas sociais e institucionais, sobretudo das altas instâncias judiciárias, em favor do bem ambiental e seu contexto atual.

Cabe à sociedade, então, interpretar o jogo hermenêutico recomendado pelo pensador Gadamer, em função das atitudes necessárias pelos órgãos estatais legitimados e a ação de exercer com maior assiduidade e eficiência o papel de fiscais e promotores da dignidade ambiental em seu próprio benefício e das gerações futuras, estas sem voz e força para agir em favor da vida presente e duradoura.

\section{REFERÊNCIAS BIBLIOGRÁFICAS}

ALEXY, Robert. Teoria dos direitos fundamentais. São Paulo: Malheiros Editores, 2008.

ALMEIDA, Custódio L.; FLICKINGER, Hans-Georg; ROHDEN, Luiz. Hermenêutica filosófica: nas trilhas de Hans-Georg Gadamer. Poa: Edipucrs, 2000, p. 149.

ARENDT, Hannah. A Condição Humana. Trad. Roberto Raposo. Rio de Janeiro: Forense, 1991.

CEZNE, Andrea Nárriman. A Teoria dos direitos fundamentais: uma análise comparativa das perspectivas de Ronald Dworkin e Robert Alexy. Revista de Direito Constitucional e 


\section{Artigo original}

Hegemonia - Revista Eletrônica de Relações Internacionais do Centro Universitário Unieuro ISSN: $1809-1261$

UNIEURO, Brasília, número 21, Julho-Dezembro de 2017, pp. 107-127.

Internacional, São Paulo, v.13, n.52, p.51-67, jul./set. 2005.

DWORKIN, Ronald. Levando os direitos a sério. Trad. Nelson Moreira. São Paulo: Martins Fontes, 2002. p. 568.

GADAMER, Hans-Georg. Verdade e Método I: traços fundamentais de uma hermenêutica filosófica (VMI). Tradução Flávio Paulo Meurer. São Paulo: São Francisco/ Vozes, 2005.

GADAMER, Hans-Georg. Verdade e Método: traços fundamentais de uma hermenêutica filosófica (VMI). Tradução Flávio Paulo Meurer. 2. ed. Petrópolis: Vozes, vol. I, 1997.

GIACOIA JÚNIOR, Osvaldo. Hans Jonas: o princípio responsabilidade. Ensaio de uma ética para a civilização tecnológica. In: OLIVEIRA, M. A. de, (Org.). Correntes fundamentais da ética contemporânea. Petrópolis: Vozes, 2000, pp.193-206.

GIL, Antonio Carlos. Como Elaborar Projetos de Pesquisa. $4^{a}$ ed. São Paulo. Atlas, 2002.

JONAS, Hans. O princípio da responsabilidade. Ensaio de uma ética para a civilização tecnológica. Contraponto. Rio de Janeiro. PUC do Rio 2006.

KEINERT, Fábio Cardoso. A questão social em Hannah Arendt. Teoria \& Pesquisa. Vol. XVI $\mathrm{n}^{\mathrm{o}}$ 01, jan. /jul. 2007.

OLIVEIRA, Jelson Roberto de. Da magnitude e ambivalência à necessária humanização da tecnociência segundo Hans Jonas. Cadernos IHU Ideias, v. 176, 2012.

RICHARDSON, Roberto Jarry. Pesquisa social: métodos e técnicas. $3^{a}$ Ed. São Paulo: Atlas, 1999.

ROHDEN, Luiz. Hermenêutica filosófica. Entre a linguagem da experiência e a experiência da linguagem. Editora UNISINOS. São Leopoldo, RS: 2012.

SANTOS, Leandro de Assis. O FENÔMENO DO JOGO E A HERMENÊUTICA DE HANS-GEORG GADAMER The phenomenon of the game and Hans-Georg Gadamer's 
Artigo original

Hegemonia - Revista Eletrônica de Relações Internacionais do Centro Universitário Unieuro ISSN: 1809-1261

UNIEURO, Brasília, número 21, Julho-Dezembro de 2017, pp. 107-127.

hermeneutics.

http://revistaseletronicas.pucrs.br/ojs/index.php/intuitio/article/viewFile/15043/10443.

Acessado em: 27.2.2016. 